\title{
Covid-19 and Common Mental Disorders in the Risk Group Population: \\ A Study in Brazilian Amazon
}

\section{Carlos Alberto Paraguassú-Chaves ${ }^{1}$, Carla Dolezel Trindade ${ }^{2}$, Simão Aznar Filho' ${ }^{2}$, Fabrício Moraes de Almeida ${ }^{3 *}$, Lenita Rodrigues Moreira Dantas ${ }^{4}$ and Gisely Beck Gonçalves Salton ${ }^{5}$}

${ }^{1} \mathrm{PhD}$ in Health Sciences - University of Brasília - UnB, Brazil and PhD in Science

- University of Havana, Cuba and Post-Doctor in Health Sciences - UnB and Degli Studi D'Aquila University - IT, Professor at the Federal University of Rondônia, Brazil

${ }^{2}$ PhD in Law - Universidad Nacional de Lomas de Zamora, Argentina and Post -doctorate - Universita deli Studi di Messina, Italy and Full Professor at the University Institute of Rio de Janeiro - IURJ, Brazil

${ }^{3} \mathrm{PhD}$ in Physics (UFC), with Post-doctorate in Scientific Regional Development (DCR/CNPq), Researcher of the Doctoral and Master Program in Regional Development and Environment (PGDRA/UNIR), Brazil ${ }^{4}$ Geographer Expert and Lawyer, Researcher of the Institute of Health Sciences and the Amazon Environment - AICSA, Brazil

${ }^{5}$ Specialist in Public Health, Volunteer Researcher at the Institute of Health

Sciences and the Environment of the Amazon - AICSA, Brazil

*Corresponding Author: Fabrício Moraes de Almeida, PhD in Physics (UFC), with Post-doctorate in Scientific Regional Development (DCR/CNPq), Researcher of the Doctoral and Master Program in Regional Development and Environment (PGDRA/ UNIR), Brazil.
Received: April 05, 2021

Published: June 12, 2021

(C) All rights are reserved by Fabrício Moraes de Almeida., et al.

\begin{abstract}
Objective: To evaluate the frequency of common mental disorders (CMD) in a population group at risk during the Covid-19 pandemic. Materials and Methods: This is a descriptive study, with a quantitative approach, a type characterized as epidemiological. An adapted version of the Self-Reporting Questionnaire (SRQ-20), the adapted PSS and the abbreviated WOHOO were used as data collection instruments. A total of 560 volunteers participated in the sample, $57 \%$ female and $43 \%$ male, with ages ranging from 35 to 85 years.

Results: The general average of proportional relative frequency for each 10 research subjects belonging to the risk group for Covid-19, resulting from the composition of the 5 factors of the SRQ-20 was 7.8, higher than the cutoff point that characterize common mental disorders (CMD). Among the factors of the PSS prevail: "anxiety for information about the disease", "fear", "sadness" and "anxiety", "fear of being infected by covid-19", "fear of dying", "frustration and boredom", "Anger", "irritability", "uncertainty" and, "having a chronic illness". The WHOQOL-bref found results that show dissatisfaction with the quality of life in this risk group. The results of the 3 instruments applied show and characterize the CMD in this studied group.

Conclusion: It can be said that this risk group suffers from CMD with symptomatic characterization of depression.
\end{abstract}

Keywords: Covid-19; Common Mental Disorders (TMC) and Risk Group 


\section{Introduction}

Pandemics are known as epidemics that spread rapidly across countries and affect a relatively large number of people [1]. Pandemics in general, generate consequences from the micro to the macro-systemic level and impose new rules and social habits for the world population and mobilizations of different natures for their containment [2]. According to Costa [3], the Covid-19 pandemic is a worldwide phenomenon with unique characteristics, in terms of its extent, speed of growth, general impact on the population and health services, and also because it occurs in a context of access to a lot of information in a very short time.

The Covid-19 pandemic is thus a strong causal factor for neurophysiological imbalances in the exposed population and especially in the vulnerable population or those at risk. Over time, with the persistence and prolongation of these hormonal, inflammatory and neurochemical imbalances, they can trigger a more serious mental disorder in the population exposed and submitted to this new condition of life.

Ahmed., et al. [4] in their studies with the population of China, indicate that there are possible psychological consequences resulting from mass confinement or social isolation, affecting all ages and especially the population at risk. According to Ahmed., et al. [4] the results showed a higher rate of anxiety, depression, harmful use of alcohol and less mental well-being compared to the usual population rates. According to Xiang., et al. [5] in general, patients with confirmation or suspicion of Covid-19 may be afraid of the consequences of the infection - potentially fatal, and those in quarantine may experience boredom, loneliness and anger. Costa [3] recognizes that groups that can respond more intensely to the stress of a crisis include: elderly people or those with chronic diseases who are at higher risk if they have Covid-19; health professionals who work in the service to Covid-19 and, people who have mental disorders, including problems related to substance use.

For Ornell., et al. [6] during epidemics, the number of people with affected mental health tends to be greater than the number affected by the infection, and it can last longer and have a higher prevalence than the epidemic itself. Mental illness involves interactions between biological and social factors and, at this moment, social factors act as strong stressors and consequently trigger and motivate depressive and anxious episodes, among other disorders [7]. And in this population group, people at risk are more susceptible to illness and death.

According to Paraguassú-Chaves., et al. [8] a significant part of the voluntary population of their research in the Brazilian Amazon, belonging to the risk group, already manifested a different and uncomfortable behavior, but without knowing how to react to the emotional discomfort in these pandemic times of Covid-19. According to Paraguassú-Chaves., et al. [8] in compulsory confinement or compulsory social isolation, with the abrupt change in the routine of life, some biopsychological manifestations are intensified as the feeling of helplessness, boredom and anger due to the loss of freedom. Other reactions of situational adjustment are manifested and are characterized by anxiety, irritability, and discomfort in relation to the new reality, a situation confirmed by Paraguassú-Chaves., et al. [9]. According to this same author, it can be affirmed even though empirically that common mental disorders, characterized by non-psychotic symptoms such as insomnia, fatigue, irritability, forgetfulness, difficulty concentrating and somatic complaints have become part of the daily life of the population at risk in the State from Rondônia, Brazilian Amazon.

Risk groups for the worsening of Covid-19 are considered to be those with chronic diseases, such as diabetes and hypertension, asthma, chronic obstructive pulmonary disease and smokers (who use tobacco), over 60 years old, pregnant women, puerperal women, children under 5 years old among others. There are recently published studies with data on risk groups linked to higher mortality from Sars-Cov-2, citing hematological diseases, including sickle cell anemia and thalassemia, advanced chronic kidney disease (grades 3, 4 and 5), immunosuppression caused by the treatment of autoimmune conditions, such as lupus or cancer, except non-melanotic skin cancer, obesity or chromosomal diseases with a state of immune fragility [10-12].

Public health interest groups are also considered, deserving special attention due to their vulnerability, health professionals, the indigenous population, prisoners and residents of long-term care facilities for the elderly [11]. Belong to the Risk Group for Infection by Covid-19, according to the Mandatory Prevention Protocol for Controlled Distance Models in some Brazilian States, people with the following conditions: people aged 60 or over; pregnant and lactating women; people with morbid obesity (those with a BMI greater than or equal to 40); immunosuppressed people; people with advanced kidney disease (grades 3, 4 and 5); people with chromosomal diseases with a weakened immune status (e.g. Down syndrome); people with chronic non-communicable diseases: severe or decompensated heart disease; severe or decompensated lung diseases (using home oxygen; asthma; COPD); diabetes mellitus; neoplasms.

Goldberg and Huxley [13] conceptualize Common Mental Disorders (CMD) as a set of non-psychotic symptoms such 
as insomnia, fatigue, irritability, forgetfulness, difficulty concentrating and somatic complaints, which designate situations of mental suffering, often not covered by the criteria diagnoses of international disease classifications [8]. These disorders are included in the frames of stress, anxiety and depression. CMDs that designate clinical conditions in individuals with symptoms of anxiety, depression or somatization and that do not meet all criteria for mental illness according to the international classification of diseases [14]. Individuals with TCM have complaints such as sadness, anxiety, fatigue, decreased concentration, somatic concern, irritability and insomnia [15].

According to Paraguassú-Chaves., et al. [8] with a new world and Brazilian scenario resulting from the Covid-19 pandemic, several studies were promptly presented as responses to the scenario of possible CMD in the population subjected to social isolation or quarantine. In the first impacting phase, it was characterized by a radical change in lifestyle, the fear of being contaminated by the invisible virus and by little being known about its behavior. The media information and the original provocation of the press almost entirely, the mismatches of information, the disjointed campaigns such as "stay at home", the absence of convincing public policies, the reduction and distance of physical contact, awakens the anguish, the anxiety and hopelessness. Everything suggests that the first reaction was acute stress related to the Covid-19 pandemic caused by a sudden and unexpected circumstance. The initial focus of apprehension is the fear of being contaminated, which does not differ much from traumatic situations such as an environmental, social or economic disaster, according to Paraguassú-Chaves [16] and Paraguassú-Chaves [17].

Costa [3] highlights that due to the period of social detachment, quarantine or isolation, reduction of stimuli, loss of income due to the impossibility of working and significant changes in routine, some reactions are common: fear of falling ill and dying; avoidance of seeking medical attention for other reasons, such as fear of becoming infected; changes in sleep, low concentration in daily tasks or the appearance of intrusive thoughts; feelings of hopelessness, boredom, loneliness and depression due to isolation; anger, frustration or irritability due to loss of autonomy and personal freedom.

Other changes are symptomatic in these groups, such as, the concern with obtaining food, medicine or personal supplies; fear of losing the source of income, for not being able to work, or being fired; fear of being socially excluded/stigmatized for becoming ill; feeling powerless to protect those close to you, or fear of being separated from family members due to quarantine/isolation; concern about the possibility of the individual or members of his family contracting Covid-19, or transmitting it to others; risk of deterioration of clinical diseases and previous mental disorders, or even the onset of mental disorders; loss in grieving processes if there are restrictions on farewell rituals; fear, anxiety or other stress reactions linked to false, alarmist or sensational news, and even to the large volume of information circulating [3].

TMC knowledge in human groups in the Brazilian Amazon and especially at risk in times of pandemics, such as Covid-19, is considered inexpressible. Some studies carried out in the Brazilian Amazon by Paraguassu-Chaves [18]; Paraguassú-Chaves., et al. [9]; Paraguassú-Chaves [16] and Paraguassú-Chaves [17] were relevant in the decisions and planning of public mental health policies, in the organization of services and in the development of prevention and treatment programs in a reality in the Brazilian Amazon. In his studies, Paraguassú-Chaves [18] identified with extreme representation the cases of post-traumatic stress states, adaptation disorder, non-organic sleep disorder, insomnia, nightmares and repeated memories about the event, amnesia, difficulty concentrating, irritability and anger, phobia, anxiety and panic, depression, loss of appetite, fatigue, dizziness, increased consumption of alcohol and medication, behavioral and emotional disorders in children and the elderly.

These disorders can condition suffering and decrease the quality of life of the affected people, also causing economic burdens on society, mainly due to the indirect costs related to absenteeism due to illness, premature diseases and early death. In addition to the fact that depressive disorders can significantly influence the results of comorbidity of diseases such as heart problems, diabetes, among many others, and are susceptible to cause dysfunctions at the family level and to have risks of physical or mental illness in their family members and coexistence [19].

Silva, Santos and Oliveira [20] carried out a reflective study based on the structuring of a narrative review of the literature on the impacts of the pandemic of the new Coronavirus on the mental health of the population and realized a generalized panic and stress on mental health in society. The findings point to an immediate psychological impact on the population as a result of the pandemic, with an increase in anxiety symptoms and even depression. The effects of the pandemic have been directly and indirectly affecting people's mental health in the most diverse aspects, which implies a worrying public health condition.

\section{Objective of the Study}

The objective of this research is to evaluate the frequency of common mental disorders in a population group at risk during the 
period resulting from the Covid-19 pandemic in Rondônia, Brazilian Amazon.

\section{Materials and Methods}

This was a cross-sectional and quantitative study, with an exploratory character, carried out with individuals between 35 and 85 years old, living in the State of Rondônia, Brazilian Amazon. This research is part of a larger project entitled "Common Mental Disorders in the Population of the Brazilian Amazon", which investigates the prevalence of mental suffering in population groups in the Amazon Region.

\section{Instruments and procedures}

The first data collection instrument was the Self-Reporting Questionnaire (SRQ-20), originally developed by Harding., et al. [21] and adapted by Paraguassú-Chaves [17] for studies in the Amazon. The Self-Report Questionnaire (SRQ-20), is an instrument that has been widely used to measure indicators of possible mental and behavioral disorders. It works as a screening tool for the detection of symptoms, suggesting the level of suspicion (presence/absence) of minor mental disorders such as depression, anxiety and stress. In the adaptation proposed by Paraguassú-Chaves [17] the SRQ-20 was evaluated considering 7 as the cutoff point, according to the trend pointed out by other Brazilian studies, such as those by Santos., et al. [22] and Gonçalves, Stein and Kapczinski [23].

The categorization was performed by 5 factors, being addressed in factor analysis 1 - decreased energy consisting of 6 variables: feels tired all the time; gets tired easily; finds it difficult to make decisions; finds it difficult to carry out their daily activities with satisfaction; has difficulty thinking clearly; he has difficulties in the service - his work is painful, it causes him suffering. Factor analysis 2 - somatic symptoms, composed of 4 variables, being: you have a headache frequently, you have an unpleasant feeling in your stomach, you have poor digestion, you have a lack of appetite. Factor analysis 3 - depressed mood, 3 variables appear, being: you feel nervous, tense or worried; has been feeling sad lately; has been crying more than usual. Factor analysis 4 on depressive thoughts consists of 4 variables, being: you have lost interest in things; he is unable to play a useful role in his life; he feels like a useless person, without help; has an idea of ending life. Finally, factor 5 organized from other symptoms of the SRQ-20, having 3 variables: sleeps poorly; it is easily frightened; has tremors in his hands.

The second instrument used was the Perceived Stress Scale (PSS) with the following variables: during the quarantine you felt: fear, sadness, anxiety, irritability, anger, fear of being infected with Covid-19, fear of dying from the disease, frustration and boredom, if you have a chronic disease, if you have a family member with a chronic disease, if you have already contracted or someone in your family has contracted covid-19, daily communications cause you anxiety and are concerned about the future.

The third instrument used was the abbreviated WHOQOL, referring to quality of life, adapted by Paraguassú-Chaves [17]. The selected variables were: how do you assess your quality of life today? how satisfied are you with your sleep ?, how satisfied are you with your sex life?, how satisfied are you with your access to health services?, with what How often do you have feelings such as bad mood, despair, anxiety and depression?

\section{Sampling}

Five hundred and eighty (560) volunteers participated in this research, being 320 (57\%) female and 240 (43\%) male, with ages varying from 35 to 85 years old. The sample granted for accessibility was a group of people considered to be at risk, that is, people of both sexes and of varying ages who declared themselves to be part of the mandatory prevention protocol of controlled distance models as a risk group for the Covid-19. To calculate the sample size, it was necessary to use some statistical method. In this sense, the systematic sampling formula presented by Barbetta [24] was used. There was no physical contact or virtual communication between the research coordinator and the volunteer respondents. Everyone who agreed to participate in the research returned the instrument by responding with free and informed non-nominative consent, that is, there was no signature, nor identification by name. The responses were returned to the research coordinator via WhatsApp and E-mail.

\section{Inclusion and exclusion criteria}

Inclusion criteria: The research involved the participation of 560 volunteers considered from the risk group for covid-19, who signed the Free and Informed Consent Form (CIF) and returned the instruments with the answered questions and are part of the risk group. Those who did not sign the informed consent form, did not answer the questionnaire and were not part of the adherence of the risk group were excluded from the study.

\section{Ethical aspects}

The research project complies with Resolution 196/96, which deals with research with human beings, of the National Health Council of Brazil. The research coordinator requested exemption from the CEP of a Higher Education Institution in Rondônia, considering that the study did not require intervention or collection of biological material and there was no possibility of embarrassment or recognition of the research subject. The 
participating subjects are volunteers and were submitted to the use of the instruments with the adaptations after the free and informed consent without nominative, that is, there was no need for the respondents to identify themselves by name or other form of identification.

\section{Data analysis}

The data of the Instruments were submitted to descriptive statistical analysis, in order to know and explain the profile of the sample. For the representation of the SRQ-10 data, the frequency was calculated for each 10 subjects surveyed. For the representation of the data of the Perceived Stress Scale (PSS), the absolute frequency ( $\mathrm{Fa}$ ) and the relative frequency ( $\mathrm{Fr}$ ) of each listed variable were calculated. In the representation of the abbreviated WHOQOL data, the relative frequency ( $\mathrm{Fr}$ ) was used according to the proposed analysis categories.

\section{Results and Discussion}

\section{Self-reporting questionnaire (Srq-20) adapted}

Data on common mental disorders (CMD) are presented according to the Iacoponi classification; Mari (1998), with adaptation for this research, in the following sequenced form. Factor 1: decreased energy; Factor 2: somatic symptoms; Factor 3: depressed mood; Factor 4: depressive thoughts and Factor 5: other symptoms of SRQ-20.

In factor 1 - decrease in vital energy, the highest relative frequencies were found in the variables "you have difficulty in the service (your work is painful, it causes you suffering") with 8.4 people with CMD in a group of 10 people, " you get tired "with 8.2," have difficulty thinking clearly with 8.2 , "feel tired all the time" with 8, "find it difficult to make decisions" with 8, "find it difficult to carry out your daily tasks activities with satisfaction "with 8 for every 10 people. The mean CMD of factor 1 was 8.1 people for every 10 people submitted to the research instrument. In factor 2 - somatic symptoms, the highest frequencies are, respectively, "you have headaches frequently" with 9.2 for every 10 people in the risk group, "you have unpleasant feelings in your stomach" and "you have poor digestion" both with 9 for each 10 people submitted to the instrument. "It has a lack of appetite" presents the lowest frequency with 5.4 people for a group of 10 . The average CMD was 8.1 for every 10 people in the risk group.

As for factor 3 - depressed mood, the highest frequencies were found in "have you been feeling sad lately" with 9.2 out of 10 , "do you feel nervous or tense or worried" with 8.7 and "have you cried more than as usual "with 7.9 for each group of 10 surveyed. The average CMD was 8.6 for every 10 people in the risk group. In factor
4 - depressive thoughts, the variables "lost interest in things" with 7 out of 10 people in the risk group, "you feel like a useless person" with 5.4 out of 10, "you can't play a role useful in your life "with 5.2 and" thought about ending your own life "with a relative frequency of 3.7 for each group of 10 people in the risk group draws special attention. The average CMD was 5.3 for every 10 people in the risk group. In factor 5 - other symptoms of SQR, the highest relative frequencies were found in "sleeps badly" with 9 out of 10, "has hand tremors" with 9, "is easily startled" with 8.2. The average CMD was 8.7 for every 10 people in the risk group (Table 1 ).

\begin{tabular}{|l|c|}
\hline \multicolumn{1}{|c|}{ Factor 1 - Decrease in Vital Energy } & CMD \\
\hline Do you feel tired all the time? & 8 \\
\hline Do you get tired easily? & 8.2 \\
\hline Do you find it difficult to make decisions? & 8 \\
\hline $\begin{array}{l}\text { Do you find it difficult to carry out your daily } \\
\text { activities with satisfaction? }\end{array}$ & 8 \\
\hline Do you have trouble thinking clearly? & 8.2 \\
\hline $\begin{array}{l}\text { Do you have difficulties in the service (is your } \\
\text { work painful, does it cause you suffering?) }\end{array}$ & 8.4 \\
\hline Average & 8.1 \\
\hline Factor 2 - Somatic Symptom & CMD \\
\hline Do you have headaches often? & 9.2 \\
\hline Do you have unpleasant feelings in your stomach? & 9 \\
\hline Do you have poor digestion? & 9 \\
\hline Do you have a lack of appetite? & 5.4 \\
\hline Average & 8.1 \\
\hline Fator 3 - Humor Depressivo & CMD \\
\hline Do you feel nervous or tense or worried? & 8.7 \\
\hline Have you been feeling sad lately? & 9.2 \\
\hline Have you been crying more than usual? & 7.9 \\
\hline Average & 8.6 \\
\hline Factor 4 - Depressive Thoughts & CMD \\
\hline Have you lost interest in things? & 7 \\
\hline Are you unable to play a useful role in your life? & 5.2 \\
\hline Do you feel like a useless person? & 5.4 \\
\hline Do you have any idea of ending your life? & 3.7 \\
\hline Average & 5.3 \\
\hline Factor 5 - Other Symptoms of SRQ-20 & 9.7 \\
\hline Do you sleep badly? & \\
\hline Are you scared easily? & 9 \\
\hline Do you have tremors in your hands? & \\
\hline Average & \\
\hline
\end{tabular}

Table 1: SRQ-20 factors for every 10 suspected CMDs. 
Perceived stress scale (PSS)

In the other symptoms arising from the Perceived Stress Scale (PSS) instrument referring to factor 6 - which feelings the quarantine generates in you, the highest frequencies in decreasing order were for the variables "are you anxious about the information you receive about the disease? through the majority of different means of communication" with $97.3 \%$, "fear" 97\%,"sadness" 97\%, "anxiety" 97\%, "fear of being infected" 96\%, "fear of dying" 94.6\%, "Anger" 91.3\%, "frustration and boredom" 93\%, "irritability" 89\%, "worries about what will happen after the pandemic, uncertainty" with $87.3 \%$.

From this sample, we found "you have a chronic disease, such as hypertension, diabetes, obesity, chronic kidney disease, asthma and other chronic diseases" with $84 \%$, "someone in the household has a chronic disease" with $47.8 \%$ and "You or someone in the family or close to the family contracted covid-19" with $28.6 \%$ (Table 2 ).

\begin{tabular}{|l|c|c|c|c|}
\hline $\begin{array}{c}\text { What feelings does quarantine gener- } \\
\text { ate in you? }\end{array}$ & YEA & \% & NO & \% \\
\hline Fear & 542 & 97 & 18 & 3 \\
\hline Sadness & 542 & 97 & 18 & 3 \\
\hline Anxiety & 542 & 97 & 18 & 3 \\
\hline Irritability & 500 & 89 & 60 & 11 \\
\hline Anger & 511 & 91.3 & 49 & 8.7 \\
\hline Fear of becoming infected & 538 & 96 & 22 & 4 \\
\hline Fear to die & 530 & 94.6 & 30 & 5.4 \\
\hline Frustration and boredom & 521 & 93 & 39 & 7 \\
\hline $\begin{array}{l}\text { Do you have a chronic disease? H: } \\
\text { hypertension; D: diabetes; O: obesity; } \\
\text { CKD: chronic kidney disease; C: cancer; } \\
\text { A: asthma; O: other }\end{array}$ & 470 & 84 & 90 & 16 \\
\hline $\begin{array}{l}\text { Does anyone in the household have a } \\
\text { chronic illness? }\end{array}$ & 268 & 47.8 & 292 & 52.2 \\
\hline $\begin{array}{l}\text { Have you or someone in the family or } \\
\text { close to the family been infected by } \\
\text { covid-19? }\end{array}$ & 160 & 28.6 & 400 & 71.4 \\
\hline $\begin{array}{l}\text { Are you anxious about the information } \\
\text { you receive about the disease through } \\
\text { the most diverse media? }\end{array}$ & 545 & 97.3 & 15 & 2.7 \\
\hline $\begin{array}{l}\text { Are you worried about what will happen } \\
\text { after the pandemic, the uncertainty? }\end{array}$ & 489 & 87.3 & 71 & 12.7 \\
\hline
\end{tabular}

Table 2: Absolute and relative frequency of the factors of the Perceived Stress Scale (PSS).

\section{Whoqol - abbreviated}

In the WHOQOL variables (factor 7) abbreviated, the highest relative frequencies were $80 \%$ with poor quality of life and $17.8 \%$ poor; $60.7 \%$ very dissatisfied and $35.7 \%$ dissatisfied with their sleep; $67.6 \%$ very dissatisfied and $26 \%$ dissatisfied with their sex life; $85.6 \%$ very dissatisfied and $11.9 \%$ dissatisfied with the provision of health services during the pandemic; and $92.5 \%$ quite often of feelings such as bad mood, despair, anxiety, depression (Table 3).

\begin{tabular}{|c|c|c|c|c|}
\hline Abbreviated WHOQOL & $\mathbf{P} \%$ & R \% & В \% & NS \% \\
\hline $\begin{array}{l}\text { How would you rate your quality } \\
\text { of life today? }{ }^{*}\end{array}$ & 80 & 17.8 & 0.0 & 2.2 \\
\hline Abbreviated WHOQOL & MI \% & I \% & S \% & MS \% \\
\hline $\begin{array}{l}\text { How satisfied are you with your } \\
\text { sleep? }{ }^{* *}\end{array}$ & 60.7 & 35.7 & 3.6 & 0.0 \\
\hline $\begin{array}{l}\text { How satisfied are you with your } \\
\text { sex life? }{ }^{* *}\end{array}$ & 67.6 & 26 & 6.4 & 0.0 \\
\hline $\begin{array}{l}\text { How satisfied are you with your } \\
\text { access to health services? }{ }^{* *}\end{array}$ & 85.3 & 11.9 & 2.8 & 0.0 \\
\hline Abbreviated WHOQOL & N \% & MP \% & B \% & NS \% \\
\hline $\begin{array}{l}\text { How often do you have feelings } \\
\text { such as bad mood, despair, } \\
\text { anxiety, depression? }{ }^{* * *}\end{array}$ & 0.0 & 2.5 & 92.5 & 5.0 \\
\hline
\end{tabular}

Table 3: Relative frequency of the abbreviated WHOQOL variables.

* P: Terrible; R: Bad; B: good; NS: do not know.

** MI: Very Unsatisfied; I: Dissatisfied; S: Pleased; MS: Very Satisfied.

*** N: Nothing; MP: Very Little; B: Quite; NS: do not know.

Distribution by sex and age

The instruments were applied to 560 people considered to be at risk group for Covid-19 and in the relative frequency of sex $57 \%$ female and $43 \%$ male. In women, CMD prevails in the age group of over 65 years old (38.8\%) and 55 to 64 years old (35.6\%). Of note is the frequency of CMD in the age groups 35 to 44 years old $(12.5 \%)$ and 45 to 54 years old (13.1\%). In males, the frequency prevails in the age group over 65 years old (40.8\%) and 55 to 64 years old (38\%). The relative frequency referring to the age group of 45 to 54 years old reaches $15.4 \%$.

The general average of the proportional relative frequency for each 10 research subjects belonging to the risk group for Covid-19, resulting from the composition of the 5 factors of the SRQ-20 was 7.8, higher than the cutoff point that characterizes common mental disorders (CMD). The frequency was also higher than those found in previous surveys conducted by Paraguassú-Chaves [16] and Paraguassú-Chaves [17]. All factors are greater than $70 \%$ or 


\begin{tabular}{|l|c|c|c|c|}
\hline \multicolumn{1}{|c|}{ Sex } & Female & \% & Male & \% \\
\hline 560 & 320 & 57 & 240 & 43 \\
\hline Age group (year) & 35 a 44 & 45 a 54 & 55 a 64 & $65+$ \\
\hline Female & 40 & 42 & 114 & 124 \\
\hline $\begin{array}{l}\text { Relative frequency } \\
\%\end{array}$ & 12.5 & 13.1 & 35.6 & 38.8 \\
\hline $\begin{array}{l}\text { Male } \\
\begin{array}{l}\text { Relative frequency } \\
\%\end{array}\end{array}$ & 14 & 37 & 91 & 98 \\
\hline
\end{tabular}

instruments. The WHOQOL - bref, developed and recommended by the WHO found results that show the quality of life of this risk group: how do you evaluate your quality of life today $(80 \%$ terrible), how do you evaluate the quality of sleep $(60.7 \%$ very dissatisfied) and $35.7 \%$ dissatisfied), how do you rate your sex life (67.6\% very dissatisfied and $26 \%$ dissatisfied), what is your satisfaction with access to health service (85.3\% very dissatisfied and $11.9 \%$ dissatisfied) and $92.5 \%$ are suffering in a bad mood, despair, anxiety and depression.

Table 4: Distribution of the population by sex and age.

7, with the exception of factor 4 referring to depressive thoughts. With these data, the worsening of common mental disorders (CMD) of this researched human group is evidenced. The SelfReporting-Questionnaire (SRQ-20) presented the following order of determination: other symptoms (8.7), depressed mood (8.6) decreased energy (8.1), somatic symptom (8.1) and depressive thoughts (5.3).

In a survey conducted in 2020 by Paraguassu-Chaves., et al. [8] with population groups in the Brazilian Amazon, including the risk group in times of the pandemic, common mental disorders (CMD) showed significant CMD results in the following order: depressed mood (8.7), other symptoms (7.9), somatic symptom (7.7), decreased energy (7.4) and depressive thoughts (4.3).

The results found with the application of PSS corroborates the worsening of common mental disorders in this risk group. The results serve as a warning to primary health care services, especially to mental and behavioral health care for this population group. Asked what feeling the quarantine generates in people, this risk group shows anxiety and depression. The PSS factors prevail in the following order of frequency: "you are anxious with the information you receive about the disease through the most diverse means of communication" (97.3\%), "fear", "sadness" and "anxiety" both with 97\%, "Fear of being infected by covid-19" (96\%), "fear of dying" (94.6\%), "frustration and boredom" (93\%), "anger" (91.3\%), "irritability" (89\%),"are you worried about what will happen after the pandemic, that is, uncertainty" (87.3\%) and,"do you have a chronic illness"? H: hypertension; D: diabetes; O: obesity; CKD: chronic kidney disease; C: cancer; A: asthma; O: other (84\%). The frequencies presented for these factors are indisputable evidence of the mental suffering to which this population is subjected.

The relative frequency of the abbreviated WHOQOL factors corroborates the results presented in the SRQ-19 and PSS

According to Duarte., et al. [2] the results indicated that being part of the risk group may have up to 1.6 times more chance of risk for CMD than other population groups. Qiu., et al. [25] found the greatest losses in this population group, which can be explained by the knowledge of the highest mortality rates among these subjects, who may then be at greater risk of suffering psychological impact during the pandemic. In the studies by Duarte., et al. [2] the results also demonstrated the effects on the mental health of the sample due to the exposure and type of information accessed about the pandemic. According to this author and his collaborators, the participants who reported being more frequently exposed to information about the dead and infected are more likely to present CMD. Neria; Sullivan [26] and Thompson., et al. [27] have already announced that the media over-spreading news about pandemics may increase the initial rates of post-traumatic stress disorder symptoms. Gao., et al. [28] found that frequent exposure to social media and news about Covid-19 would be associated with increased risk of anxiety and depression symptoms.

What can happen after the pandemic, uncertainty, concern for physical health and risk of death are the most likely to happen in this context of pandemonium, generating a factor that afflicts and appears to have a negative impact on the mental health of the population, mainly in the group at risk for covid-19. The data from the study by Duarte., et al. [2] demonstrated that participants who are experiencing economic losses in the context of the Covid-19 pandemic are 1.4 times more likely to be at risk for CMD than people who have not experienced such losses. According to Frasquillo., et al. [29] the situation is more aggravated when there is a previous prevalence of CMD.

In the study by Duarte., et al. [2] the evidence suggests that being a woman increases the chance of having CMD by 2.73 times, that is, more than double when compared to men. The studies "Why is depression more common among women than among men"? de Kuehner [30] and "Sexual selection and gender differences in the prevalence of externalizing disorders in childhood and internalizing disorders in adolescence", by Martel [31], corroborate with a study by Duarte., et al. [2]. 
According to Paraguassú-Chaves., et al. [8] and ParaguassúChaves., et al. [9] the Covid-19 pandemic impacts the routine of these people who have characteristic symptoms of depression, anxiety, insomnia, increased cardiovascular problems and suicidal thoughts. According to Castro; Garcia [32] Anxiety disorder is a perception of constant restlessness. The World Health Organization (WHO) itself recognizes the high prevalence of mental psychiatric disorders related to stress, depression and other psychological sequelae in risk groups. According to Leite [33] depression, excessive alcohol consumption, post-traumatic stress and even suicide are some of the sequelae that can affect people in situations of major humanitarian crisis and that these psychological impacts can extend for up to 15 years after the traumatic events.

This research identifies well-defined symptoms of depression. Among the consequences are the symptoms we already know: sadness, apathy, demotivation, difficulty concentrating, loss of interest in daily activities, high frequency of people who have lost interest and willingness to do things that were once pleasurable (things that were pleasant before, today they are not capable of causing satisfaction and joy); difficulty in concentration and constant tiredness; indifference to affection; changes in mood (episodes of irritation, apathy, anger, impatience, etc.); I cry more often, a manifestation of sadness (sometimes crying without a plausible reason), among others.

In addition to these psychological characteristics, another group of physical sensations was also found with significant frequency. Digestive problems (gastrointestinal pain is very common in depressives). There is often the occurrence of irritable bowel syndrome, which causes abdominal pain, flatulence and changes in bowel habits). Headache (the individual with can accumulate emotional symptoms, frustrations, fears and insecurities, and somatize them by discharging them into the body through an unconscious process, which ends up causing headache-like pain). Sleep disorders (or the patient sleeps too much, seeking sleep as an escape from reality, or is unable to sleep, because he cannot disconnect from the problems that led to depression). Tiredness or fatigue (without adequate production of the neurotransmitters serotonin, norepinephrine and dopamine), the depressive person experiences a state of prostration, with symptoms such as weakness, tiredness, lack of courage and lack of initiative to perform any activity. Body aches (the symptoms of fatigue and tiredness typical of the depressive condition end up compromising an adequate posture when the individual performs his daily activities, worsening the sensation of tension and muscle pain, especially in the back and chest - which can be aggravated by sedentary lifestyle). Changes in appetite and weight (lack or excess of appetite are often associated with depression). Among other symptoms, low immunity. The physical and mental malaise triggers an uncontrolled release of hormones that affects the defense cells, causing a low immunity and leaving the person more vulnerable to colds, herpes and colds.

Well-known authors such as Bich., et al. [34]; Seto., et al. [35]; Warraich; Zaidi and Patel [36]; Vineis [37] confirm that populations exposed to adverse situations have emotional sequelae and worsening of the state of post-traumatic stress. Sleep disorders, insomnia, nightmares and repeated memories about the drastic and unexpected event, whether social, environmental, economic or of any nature, memory loss, difficulty concentrating, irritability, anger and anxiety are references that can and should be considered in the interpretation from the studies by Feng., et al. [38]; Vineis [37]. Phobias, panic and depression were found by Warraich; Zaidi and Patel [36]; Paranjothy., et al. [39]. Lack of appetite and fatigue were symptoms found by Fundter., et al. [40] (2008); Kovats [41]. Regarding the thoughts of taking his own life, Vineis (2010) confirms this extreme and worrying situation.

\section{Conclusion}

560 volunteers participated in this research, being 320 (57\%) female and 240 (43\%) male, with ages varying from 35 to 85 years old. Age prevails in people over 65 in both sexes, with a relative frequency of $38.8 \%$ of women and $40.8 \%$ of men. The general average of relative frequency resulting from the composition of the 5 factors of the proportional SRQ-20 for each 10 subjects of the research belonging to the risk group for Covid-19, was 7.8, higher than the cutoff point that characterizes common mental disorders (CMD). All factors are greater than $70 \%$ or 7 , with the exception of factor 4 referring to depressive thoughts.

The results of the PSS instrument confirm the CMD picture. All symptoms are greater than $80 \%$, including fear, sadness, anxiety, irritability, anger, fear of contagion, fear of dying from the disease, frustration and boredom, have a chronic disease and others, are anxious for information received about the disease and is concerned about the uncertainty. The only exceptions were even considered worrying, another person in the family or residence has a chronic illness with almost $50 \%$ and you or someone in the family or close to the family fell ill in Covid-19, with about $30 \%$. In the variables or factors of the abbreviated WHOQOL, the highest relative frequencies are negatively related to quality of life, quality of sleep, sexual life, disappointment with health services and feelings such as bad mood, despair, anxiety, depression. All factors, 
indicators and variables are considered strong evidence of CMD with symptomatic characterization of depression.

\section{Bibliography}

1. Morens DM., et al. "What is a pandemic?". The Journal of Infectious Diseases 200.7 (2009): 1018-1021.

2. Duarte MQ., et al. "COVID-10 e os impactos na saúde mental: uma amostra do Rio Grande do Sul, Brasil". Ciência and Saúde Coletiva 25.9 (2020).

3. Costa FB. "A Saúde Mental em Meio à Pandemia Covid-19". Secretaria de Saúde. GDF. Brasília (2020).

4. AHMED MZ., et al. "Epidemic of COVID-19 in China and Associated Psychological Problems". Asian Journal of Psychiatry 51 (2020): 102092.

5. Xiang YT., et al. "Timely mental health care for the 2019 novel coronavirus outbreak is urgently needed". Lancet Psychiatry 7.3 (2020): 228-229.

6. Ornell F., et al. "Medo pandêmico" e COVID-19: ônus e estratégias para a saúde mental". Brazilian Journal of Psychiatry (2020).

7. Silva AG., et al. "Saúde mental: por que ainda é importante no meio de uma pandemia". Brazilian Journal of Psychiatry (2020a).

8. Paraguassú-Chaves CA., et al. "Self-Reporting Questionnaire como instrumento de avaliação de transtornos mentais comuns em grupo populacional da Amazônia". In: Biodiversidade e Biotecnologia no Brasil 2. SS editora (2020a).

9. Paraguassú-Chaves CA., et al. "Assessment of mental suffering in a population affected by the Madeira River flood in the Brazilian Amazon". International Journal of Advanced Engineering Research and Science (IJAERS) 7.2 (2020b): 155-165.

10. BRASIL. Organização Pan-Americana de Saúde. Folha informativa COVID-19: Escritório da OPAS e da OMS no Brasil. Atualizado em 25 de agosto (2020a).

11. SES. Secretaria de Estado de Saúde. Estado do Mato Grosso do Sul. Vigilância em Saúde. Gerência Técnica de Influenza e Doenças Respiratórias. Nota Técnica Covid-19 Revisão 14. Campo Grande:SES-MS. (2020): 28.

12. BRASIL. Ministério da Saúde. Secretaria de Vigilância em Saúde. Guia de Vigilância Epidemiológica: Emergência de
Saúde Pública de importância nacional pela doença pelo Coronavírus 2019: Vigilância de Síndromes Respiratórias Agudas: COVID-19. Brasília-DF, 05 de Agosto de (2020b): 58.

13. Goldberg D and Huxley P. "Common mental disorders: a biosocial model”. London: Tavistock/Routledge (1992).

14. Cerchiari Ean., et al. "Prevalência de Transtornos Mentais Menores em Estudantes Universitários". Estudos Psicológicos 10.3 (2005): 413-420.

15. Kac G., et al. "Fatores relacionados à prevalência de morbidades psiquiátricas menores em mulheres selecionadas em um Centro de Saúde no Rio de Janeiro, Brasil”. Cadernos de Saúde Pública 22.5 (2006): 999-1007.

16. Paraguassú-chaves CA. "Studies of Common Mental Desorders in the Brazilian Amazon". Editora Temática. Porto Velho (2020a).

17. Paraguassú-chaves CA. "Relatório Fiero". AICSA. Porto Velho (2020b).

18. Paraguassú-chaves CA. "Doenças invisíveis - sofrimento mental na população exposta à enchente do rio Madeira". Debate em Ação: Discussão Científica. Porto Velho (2015).

19. Soegaard HJ. "Undetected CommonMental Disorders in LongTermSickness Absence". International Journal of Family Medicine (2012).

20. Silva HGN., et al. "Efeitos da pandemia no novo Coronavírus na saúde mental de indivíduos e coletividades". Journal of Nursing and Health 10 (2020): e20104007.

21. Harding TW., et al. "Mental disorders in primary health care: a study of their frequency and diagnosis in four developing countries". Psychological Medicine 10 (1980): 231-241.

22. Santos KO., et al. "Avaliação de um instrumento de mensuração de morbidade psíquica: estudo de validação do Self-Reporting Questionnaire (SRQ-20)”. Revista Baiana de Saúde Pública 34.3 (2011): 544-560.

23. Gonçalves DM., et al. "Avaliação de desempenho do Self-Reporting Questionnaire como instrumento de rastreamento psiquiátrico: um estudo comparativo com o Structured Clinical Interview for DSM-IV-TR". Cadernos de Saúde Pública 24.2 (2008) 
24. Barbetta PA. "Estatística aplicada às Ciências Sociais”. 1. ed. Florianópolis: UFSC (1994).

25. QIU J., et al. "A nationwide survey of psychological distress among Chinese people in the COVID-19 epidemic: implications and policy recommendations". General Psychiatry 33.2 (2020): e100213.

26. Neria Y., et al. "Understanding the mental health effects of indirect exposure to mass trauma through the media". JAMA 306.12 (2011): 1374-1375.

27. Thompson RR., et al. "Media exposure to mass violence events can fuel a cycle of distress". Science Advances 5.4 (2019): eaav3502.

28. Gao J., et al. "Mental health problems and social media exposure during COVID-19 outbreak". Plos One 15.4 (2020): e0231924.

29. Frasquillo D., et al. "Mental health outcomes in times of economic recession: a systematic literature review". BMC Public Health 16 (2015): 115.

30. Kuehner C. "Why is depression more common among women than among men?" Lancet Psychiatry 4.2 (2011): 146-158.

31. Martel MM. "Sexual selection and sex differences in the prevalence of childhood externalizing and adolescent internalizing disorders". Psychiatry Bulletin 139.6 (2013): 1221-1259.

32. Castro M de and GARCIA F. "Pesquisa sobre a Saúde Mental das Famílias Atingidas pelo Rmpimento da Barragem do Fundão em Mariana". Universidade Federal de Minas Gerais. Núcleo de Pesquisa Vulnerabilidades e Saúde (NAVeS - UFMG). Belo Horizonte (2019).

33. Leite RM. "Relatório Assistência da Saúde Mental”. Instituto de Psiquiatria (Ipq) do Hospital das Clínicas da Faculdade de Medicina da USP (FMUSP). São Saúlo (2019).

34. Bich TH., et al. "Impacts of flood on health: epidemiologic evidence from Hanoi, Vietnam”. Global Health Action (2011): 4.

35. Seto EY., et al. "Impact of changing water levels and weather on Oncomelania hupensis hupensis populations, the snail host of Schistosoma japonicum, downstream of the Three Gorges Dam". Ecohealth 5.2 (2008): 149-158.

36. Warraich H., et al. "Floods in Pakistan: a public health crisis". Bulletin of the World Health Organization 89 (2011): 236-237.
37. Vineis P. "Climate change and the diversity of its health effects". International Journal of Public Health 55.2 (2010): 81-82.

38. Feng S., et al. "Social support and posttraumatic stress disorder among flood victims in Hunan, China". Annals of Epidemiology 17.10 (2007): 827-833.

39. Paramjothy S., et al. "Psychosocial impact of the summer 2007 floods in England". BMC Public Health 11 (2011): 145-149.

40. Fundter DQ., et al. "Health impacts of large-scale floods: governmental decision-making and resilience of the citizens". Prehospital and Disaster Medicine 23.4 (2008): s70-73.

41. Kovats RS. "Will climate change really affect our health? Results from a European Assessment". The Journal of the British Menopause Society 10.4 (2004): 139-144.

Volume 5 Issue 7 July 2021

(C) All rights are reserved by Fabrício Moraes de Almeida., et al. 